\title{
B3 Lesions: Radiological Assessment and Multi-Disciplinary Aspects
}

\author{
Sylvia H. Heywang-Köbrunner ${ }^{a, b}$ \\ aReferenzzentrum Mammographie München, \\ ${ }^{\text {b} R a d i o l o g i e ~ H a u d h a u s e n, ~ M u ̈ n c h e n, ~}$ \\ 'Institut für Pathologie, TU München, Germany
}

\author{
Astrid Hacker $^{\mathrm{a}}$ Stefan Sedlacek ${ }^{\mathrm{a}}$ Heinz Höfler ${ }^{\mathrm{c}}$
}

\section{Key Words}

B3 lesion - Biopsy · Underestimate - Atypical hyperplasia . Breast

\section{Summary}

B3 lesions comprise different histopathological entities that are considered benign but 'of unknown biological potential'. These entities may act as risk indicators (for both breasts) or as non-obligatory precursors of malignancy. Being diagnosed at percutaneous breast biopsy, an additional risk of underestimate exists. Imaging appearances, histopathological appearance and risk of associated malignancy are presented. B3 lesions of high risk, which thus should usually be excised, include atypical ductal hyperplasia $(A D H)$, pleomorphic or necrotic type of lobular neoplasia (LIN 3), and papillary lesions with atypias. Intermediate risk may be associated with classic lobular carcinoma in situ (LIN 2) or flat epithelial atypia (FEA), and low risk with radial sclerosing lesions (RSLs) and papillary lesions without atypias. LIN 1 is mostly an incidental finding acting as risk indicator. Follow-up is adequate if the initial diagnostic problem is solved. According to international guidelines, risk and subsequent recommendations should be discussed for each individual patient, taking into account biological risk, representative sampling, lesion size, lesion extent, percentage of lesion removal, other individual risks, and the possibility of surveillance. With vacuumassisted breast biopsy (VABB), surgery may be avoided for more of the small lesions at low risk. Further data collection and diligent evaluation may help to better assess the individual risk, to better adapt treatment recommendations and avoid overtreatment.

\author{
Schlüsselwörter \\ B3-Läsion · Biopsie · Upgrade · Atypie · Brust
}

\section{Zusammenfassung}

B3-Läsionen beinhalten verschiedene histopathologische Entitäten, die als benigne, aber mit «unklarem biologischen Potenzial» eingestuft werden. Diese Entitäten werden als Risikofaktor (für beide Brüste) oder als nicht obligate Präkanzerose betrachtet. Bei der Diagnosestellung mittels Stanzbiopsie muss davon ausgegangen werden, dass B3-Läsionen auch Teil einer höhergradigen, also malignen Veränderung sein können (sogenanntes Upgrade). In der vorliegenden Arbeit werden bildgebende Befunde mit der Histopathologie korreliert und deren Malignitätsrisiko diskutiert. Zu den B3-Läsionen mit hohem Malignitätsrisiko gehören die atypische duktale Hyperplasie (ADH) und die pleomorphe oder nekrotische lobuläre Neoplasie (LIN 3). Diese sollten exzidiert werden. Intermediäres Risiko ist assoziiert mit dem klassischen lobulären Carcinoma in situ (LIN 2) oder auch der flachen epithelialen Atypie (FEA). Niedriges Malignitätsrisiko haben radiäre Narben und papilläre Läsionen ohne Atypien (LIN 1). LIN 1 sind meist inzidente Befunde, die als Risikoindikator gelten. Kontrolluntersuchungen sind bei B3-Läsionen mit niedrigem Risiko angemessen, wenn auch das initiale diagnostische Problem gelöst ist. Gemäß den internationalen Leitlinien muss diese Empfehlung für jeden Fall individuell diskutiert werden. Dabei ist es wichtig, Folgendes in die Überlegung mit einzubeziehen: biologisches Risiko, Repräsentativität der Probe, Größe und Ausdehnung der Läsion, prozentuale Entfernung der Läsion, andere individuelle Risiken und die Überwachbarkeit der Patientin. Gerade bei kleinen Läsionen mit niedrigem Malignitätsrisiko kann mittels Vakuumbiopsie eine große Operation vermieden werden. Weitere Datenerhebung und präzise Evaluation werden auch zukünftig dabei helfen, das individuelle Risiko besser einzuschätzen, die Therapien besser anzupassen und Übertherapien zu vermeiden.

\begin{tabular}{ll}
\hline KARGER & $\oplus$ 2010 S. Karger GmbH, Freiburg \\
Fax +497614520714 & Accessible online at: \\
Information@Karger.de & www.karger.com/brc \\
www.karger.com &
\end{tabular}




\section{Introduction}

B3 lesions include the following main entities: atypical ductal hyperplasia (ADH), lobular neoplasia (LIN) including lobular carcinoma in situ (LCIS) and atypical lobular hyperplasia (ALH), radial sclerosing lesions (RSLs), papillary lesions, flat epithelial atypia (FEA), fibroepithelial lesions, and other rare entities.

The entities underlying the B3 lesions may occur in needle biopsies, in excisional biopsies, or in mastectomy specimens. The term B3, as described in the European Guidelines [1], is, however, used when the above entities are diagnosed at needle biopsy. The categories B1-B5 serve for a systematic communication between pathologists and between pathologists, clinicians and radiologists. Overall, they comprise entities of lesions of a comparable risk profile, for which similar treatment decisions are needed. B3 lesions are defined as benign lesions of unknown biological potential.

In contrast to open biopsy, only a small volume of tissue is available from needle biopsies.

Thus, for all needle biopsies, close correlation of imaging and histopathology is needed to decide whether the biopsy is representative and explains the imaging findings. A non-representative result occurs if the lesion is missed by needle biopsy (by some targeting error). It may also be caused by a sampling error. Sampling error occurs in lesions that are composed of inhomogeneous tissue or in which small nests of tumor cells are surrounded by large amounts of unspecific tissue (such as fibrosis or necrosis). Sampling error means that the biopsy was correctly taken from the lesion (for example from a lobular carcinoma), but the acquired tissue does not represent the most concerning area (the files or nests of cancer cells) within this lesion. It represents only unspecific tissue components (like fibrosis) and thus leads to a false-negative result.

For B3 lesions, this question is of special concern since B3 lesions may occur within or in the periphery of higher-grade lesions such as ductal carcinoma in situ (DCIS) or invasive breast cancer.

B3 lesions may also function as a "non-obligate precursor of malignancy'; that is, (if left in the breast) they might later on develop into a DCIS or invasive carcinoma. Finally, some B3 lesions are considered 'risk indicators'. That is, they indicate an increased possibility that the patient may develop a breast cancer in any location of the same or the contralateral breast.

Based on this special situation, it is generally recommended that all needle biopsies yielding B3 lesions be discussed in a multi-disciplinary conference [1-5]. In this conference, imaging, histopathology, patient age and individual risk factors are considered to develop an optimum recommendation for the patient.

Options for this recommendation include surgical excision, short-term imaging follow-up and/or chemoprevention using anti-estrogen treatment. Considering the many factors that may have an impact on the patient's individual prognosis and the ongoing research in this field, there exists no generally applicable detailed algorithm or guideline (yet) that would permit to systematically deduce the recommendation from the type of B3 lesion or its imaging features.

This article gives an overview on the imaging presentations and on the risks associated with the various histopathological entities. These and other factors influencing multi-disciplinary decisions are discussed.

\section{Prevalance of B3 Lesions, Imaging and Overall Risk}

B3 lesions may coexist with various other benign or malignant changes. Frequently, B3 lesions are detected during histopathological assessment of image-detected abnormalities. The reason is that the imaging features of B3 lesions partly overlap with those of early malignancy and partly with benign changes. Percutaneous biopsy of the B3 lesion is performed with the intent to detect (or exclude) malignancy. Some B3 lesions may just be detected incidentally during a percutaneous biopsy that is performed to assess a different entity. The B3 lesion is, however, not associated with the radiological findings that prompted biopsy.

With increasing use of mammographic screening, an increased detection rate of $\mathrm{B} 3$ lesions has been observed $[6,7]$. The reported prevalence of $\mathrm{B} 3$ lesions among percutaneous breast biopsies ranges between 3 and 10\% [7-12]. An interim evaluation of our screening program yielded $8.2 \%$ B3 lesions among 3,925 percutaneous breast biopsies documented between 7/2006 and 9/2008 [13].

Some B3 lesions may also be visible on ultrasound (US); some may be detected by US. Their number is smaller than that of B3 lesions detected by mammography, a fact that is understandable due to the generally lower sensitivity of US for small lesions and due to the limited detection of microcalcifications in particular. With US-guided biopsies being the easiest and best-tolerated interventions, the vast majority of mammographically detected lesions that are visible by US (at least in retrospect) undergo US-guided core needle biopsy (CNB). The remaining lesions need to undergo stereotactic breast biopsy, which in our screening program largely (> 95\%) has been stereotactic vacuum-assisted breast biopsy (VABB).

In our screening program, approximately $4.7 \%$ of the biopsies performed as CNB (usually under US guidance) yielded a B3 lesion, while $14.5 \%$ of the stereotactic VABBs yielded a B3 lesion [13].

Few reports exist on the use of magnetic resonance imaging (MRI) for B3 lesions. One publication [14] analyzed the use of MRI for further differentiation of 79 B3 lesions. 55/79 B3 lesions did not enhance. The negative predictive value of non-enhancing B3 lesions (concerning the presence of malignancy at excision) was $98 \%$. This yet existing experi- 
ence is still too limited for general recommendations. However, it might be worth to further investigate.

Unfortunately, however, the additional use of MRI could even increase the overall number of detected B3 lesions [15]. In a multicenter study on 517 MR-guided VABBs of MR-detected breast lesions, we reported $6.2 \%$ B3 lesions $(3.3 \%$ ADH plus $2.9 \%$ papillary lesions) [16]. Other large series (> 70 cases) reported up to $14 \%$ B3 lesions among MR-guided VABBs [17-20].

Another retrospective study examined the use of MRI for follow-up of 135 patients with $\mathrm{ADH}$ and 47 patients with LCIS [21]. The authors reported a very high rate of false-positive biopsies ( $25 \%$ of the patients) and an extraordinary rate of 6-month follow-up recommendations (48\%) with a fairly low overall yield of malignancy ( 6 breast cancers in 5 patients detected by MRI, 2 interval cancers). Their conclusion was that MRI is not generally recommended in these patients.

As mentioned above, B3 lesions may coexist with highergrade lesions; some may act as non-obligatory precursor of a higher-grade lesion and others may indicate a generally increased risk of breast cancer in either breast. Unless another entity of higher risk coexists, B3 lesions, however, still represent a benign entity.

So, whenever percutaneous breast biopsy yields a B3 lesion, the risk of missing an associated malignancy is counterchecked by assessing the risk associated with the given histopathological entity, with its imaging presentation, with the probability of representative removal. The latter depends on the expected homogeneity of the lesion, the volume of the harvested tissue and its relation to the expected lesion extent. Based on these considerations and further individual risks of the patient, for part of the B3 lesions excision is chosen while for those with lower risk follow-up is usually recommended.

In our screening program, excision has been recommended for about $70 \%$ of B3 lesions diagnosed at US-guided biopsy versus $55 \%$ of lesions diagnosed at stereotactic VABB [13].

We are not aware of published data on biopsy rates among B3 lesions detected by MR-guided biopsy.

According to an overview of literature data by Houssami et al. [8], the reported rate of $\mathrm{B} 3$ lesions that undergo subsequent excision and eventually contain higher-grade lesions (DCIS or invasive carcinoma) ranges around $30 \%$.

In a large series published by Houssami et al. (on 4,035 consecutive percutaneous breast biopsies), underestimates among excised B3 lesions amounted to $35 \%$ [8, 22]. 2/3 of the upgrades were upgrades from B3 to DCIS, while $1 / 3$ were upgrades to invasive breast cancer. No significant difference in the rate of upgrades was reported for lesions presenting with microcalcifications versus lesions presenting as mass or architectural distortion. However, the rate of underestimates increased with lesion size (18\% of 210 lesions $<20 \mathrm{~mm}$ were upgraded versus $48 \%$ of 69 lesions $>20 \mathrm{~mm}$ ). The rate of upgrades was approximately $50 \%$ higher with $\mathrm{CNB}$ than with $\mathrm{VABB}$, which may be explained by the larger volume of tissue removed by VABB. Finally, underestimates were significantly more frequent among B3 lesions with (44\% on average) versus without atypical ductal or lobular hyperplasia $(18 \%)$. Based on this observation, Houssami et al. [22] and Londero et al. [23] suggested to subdivide B3 lesions into B3 lesions at higher risk (ADH and LIN) and those at low risk (papillary lesions, RSLs, FEA, rare lesions and fibroepithelial tumors).

According to the experience from our screening program, upgrades occurred in approximately $30 \%$ of the excised B3 lesions that were seen on US, as compared to $20 \%$ of the excised lesions that were diagnosed at stereotactic VABB. Reported underestimates after MR-guided VABB range from 0 to $30 \%$, on average around $15-20 \%$ [17-19]. In our multicenter study of MR-guided VABB, 16\% underestimates occurred among MR-detected B3 lesions that underwent excision.

B3 lesions may occur as pure or mixed lesions or may (as mentioned above) be associated with higher-grade lesions such as DCIS or invasive breast cancer. Of course, for any decisions concerning patient management, the lesion with the highest risk needs to be considered as the leading lesion.

The following more detailed information refers to either pure lesions or to mixed lesions. In mixed lesions, the lesion with the highest risk is considered the leading lesion, for which the appropriate treatment decision is needed.

\section{Atypical Ductal Hyperplasia}

Due to the fact that (based on the small amount of available tissue) percutaneous breast biopsies may not permit to distinguish between $\mathrm{ADH}$ and DCIS, some authors suggest to use the term 'atypical proliferation of ductal type' instead of $\mathrm{ADH}$ whenever the diagnosis is based on tissue from a percutaneous biopsy. The final decision ADH versus DCIS is then based on the result after excision. Since the vast majority of publications just uses the term $\mathrm{ADH}$, we have not made this distinction.

ADH shows cellular changes identical to those of a lowgrade DCIS. However, the amount of changes is less than that of DCIS, comprising less than a terminal ductal lobular unit (TDLU) or less than $2 \mathrm{~mm}$. This explains why with a small volume of sampled tissue upgrades are more probable than with a larger volume of tissue.

On mammography, ADH may present with microcalcifications. Often, the microcalcifications are granular, sometimes coarse, sometimes fine. The latter is associated with a lower probability of malignancy. The microcalcifications may be grouped, exhibit ductal or regional distibution and often show at least some polymorphism. ADH may also present as mass with or without microcalcifications. Atypias may be contained in fibroadenomas, papillomas or within non-tumorous benign changes. Finally, ADH may occur with radial scars.

For all needle biopsies (CNBs or VABBs, US-guided or stereotactically guided biopsies), the rate of underestimates 
has been reported as high as $44 \%$ (confidence interval (CI): $36-52 \%$ ) for $\mathrm{ADH}[8,24]$.

For larger series using $11 \mathrm{G} \mathrm{VABB}, \mathrm{ADH}$ upgrades ranged around $13.5-27 \%$ [11-13, 24-29]. According to Jackmann et al. [24], most underestimates (among 104 ADH lesions diagnosed at $11 \mathrm{G}$ stereotactic $\mathrm{VABB}$ ) concerned upgrades to DCIS; only few concerned upgrades to invasive carcinoma. Even though small lesion size and mammographically complete removal of the lesion indicated a lower probability of an underestimate, they could not define a sufficiently reliable combination that would permit not to excise the lesion. For US-guided $\mathrm{CNB}$, the reported rates of upgrades are usually higher than for lesions diagnosed at stereotactic VABB, usually $>30 \%[11-13,30,31]$.

Due to the non-negligible number of underestimates to date, usually excision is recommended when $\mathrm{ADH}$ is diagnosed at percutaneous breast biopsy. Exceptions may concern elderly patients or patients who suffer from severe other disease.

Figure 1 shows a case of an ADH diagnosed at VABB, which eventually proved to be a DCIS underestimate. Figure 2 demonstrates an example of MR-detected ADH.

\section{Lobular Neoplasia}

Overall, LIN occurs in less than $1 \%$ of the needle biopsies. It comprises ALH and LCIS.

Whereas LIN initially was just considered a risk indicator [32], today it is considered a non-obligate precursor of malignancy and a risk indicator. This interpretation is based on the fact that - even though the presence of LIN is associated with a bilaterally increased risk of malignancy and even though malignancy may include DCIS, invasive ductal carcinoma (IDC) or invasive lobular carcinoma (ILC) - invasive malignancy is 3 times more frequent in the involved breast, and ILC is more frequent than IDC [33]. This latter perception appears to be supported by genetic profiling of the cancers detected in areas of LIN [34].

This debate is accompanied by a debate on optimum clinical management, which varies between systematic surgical excision and follow-up strategies.

While morphological changes are the same for ALH and LCIS, with LCIS the lobules are distended by ample amounts of atypical cells. LCIS is associated with at least twice the rate of invasive malignancy than ALH. However, genetic profiles of LCIS and ALH may show differences [34]. The different risk levels are also expressed in the other nomenclature used in the literature, which uses the terms lobular intraepithelial neoplasia (LIN) grade 1, 2 or 3. In this nomenclature, LIN 1 corresponds to ALH while LIN grade 2 is consistent with classic LCIS. LIN 3 corresponds to lesions with marked distended acini, often with central necrosis, and those composed of either severely pleomorphic cells or pure signet ring cells.

Many LIN lesions have no characteristic imaging features: They may incidentally occur in or adjacent to areas of micro- calcifications, in fibroadenomas or within other benign changes, without being associated with the imaging features of the concomitant lesion that caused biopsy (microcalcifications, masses, architectural distortions). The majority of LIN lesions $(>80 \%)$ are detected in association with microcalcifications. Some of the LIN lesions occur adjacent to RSLs or coexist with other B3 lesions.

One special subtype of LIN, pleomorphic LIN, may be associated with comedo-type casting microcalcifications. This rare type is associated with invasive breast cancer more often, i.e. in $25-67 \%$ of the cases [35-37]. Therefore it should be treated like a DCIS (excision followed by radiation therapy) and is usually classified as B5 lesion. Figure 3 gives an

Fig. 1. Patient with a diagnosis of $\mathrm{ADH}$ at $\mathrm{VABB}$. The microcalcifications were partly removed. Final histology yielded DCIS grade 2 .
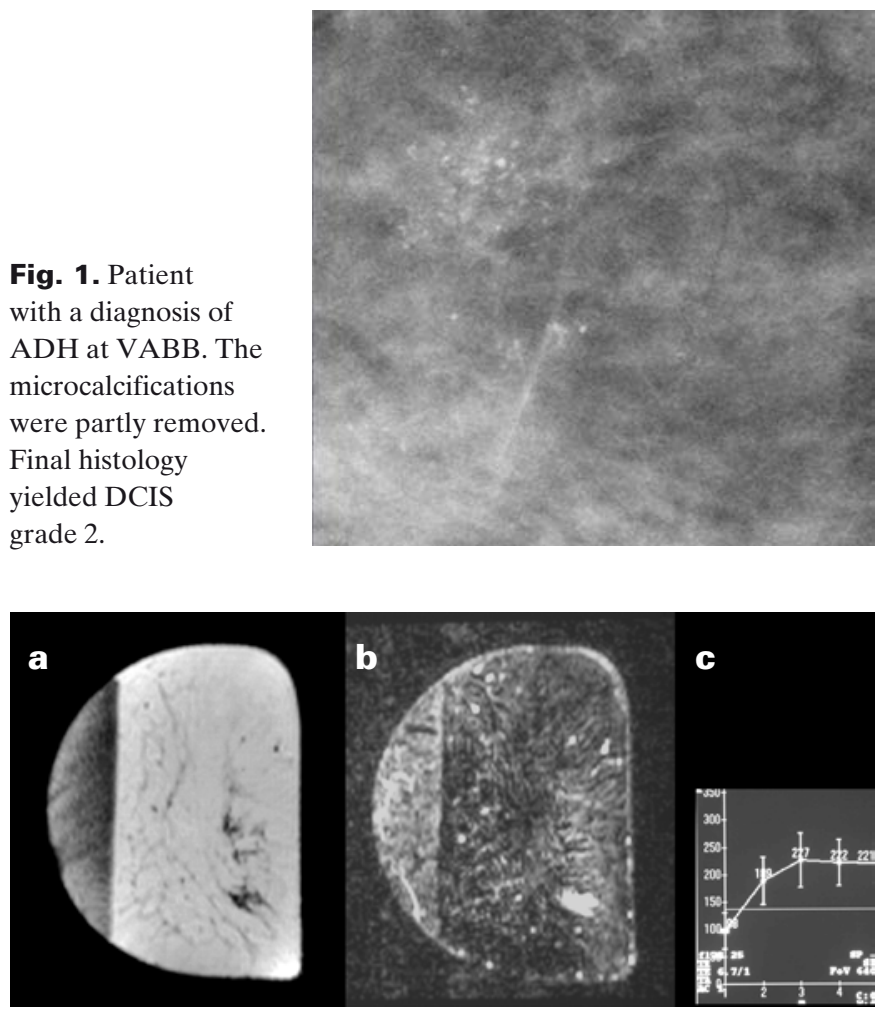

Fig. 2. The lesion was MR-detected within an area of asymmetric breast tissue. The enhancement was considered suspicious of malignancy. MR-guided VABB yielded ADH, a diagnosis that was confirmed after excision. (a) Precontrast image, (b) subtraction image, (c) enhancement curve.

Fig. 3. Pleomorphic lobular neoplasia grade 3 , diagnosed at $\mathrm{VABB}$ and confirmed at excision. Based on the histopathological features and the known high risk, this lesion is considered comparable to DCIS which should be considered concerning the recommendation of treatment.

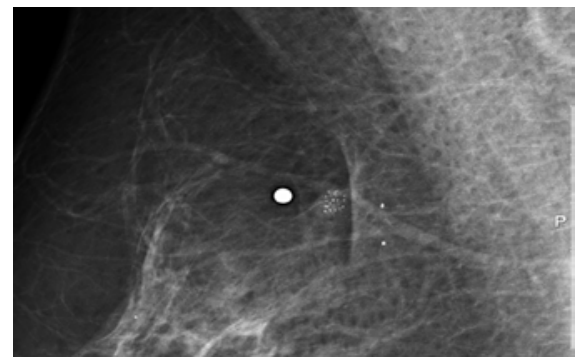


example. Based on difficulties of distinguishing this type from a DCIS with lobular cancerization, this type of LIN may falsely be classified as DCIS, which, however, has no therapeutic consequences. (In case of doubts immunochemical staining is possible.)

LIN may be associated with DCIS in mixed lesions, and which is most important - areas of LIN may constitute part of an ILC. Thus, whenever LIN is diagnosed at CNB, sampling error has to be diligently considered.

On US, LIN has been reported to occur associated with a hypoechoic lesion or with unspecific architectural changes. On MRI, we have seen regional areas of patchy or milky enhancement (similar to both benign changes or DCIS) or small enhancing masses. Enhancement curves are usually uncharacteristic (mostly delayed, sometimes plateau-type enhancement). Thus, to date, it is not yet clear whether LIN has characteristic MRI findings that are distinct from other concomitant or underlying benign enhancing changes (such as adenosis). Figure 4 demonstrates the diagnostic difficulties in a patient whose benign diagnosis has been proven by MR follow-up without change for more than 5 years after histologically verified diagnosis of LIN (incidental finding after $\mathrm{VABB}$ of microcalcifications).

Overall, the reported rates of upgrades after LIN diagnosed at percutaneous biopsy vary between 19 and 58\% [22, $23,38,39]$. Upgrades are by far more frequent with LIN 3 and pleomorphic LIN than with classic LIN grade 1-2. If followup is considered instead of excision (mainly with LIN 1 or 2), it is, however, important to countercheck whether the biopsy was representative and solved the initial question. Thus, it is necessary to clarify whether the obtained histology can explain the initial imaging finding that prompted biopsy (LIN 1 or 2 usually does not explain microcalcifications, for example) and whether biopsy of the initial area of concern is thus representative.

\section{Radial Sclerosing Lesions}

RSLs usually present as architectural distortion on mammography. As initially described by Tabar, radial lesions may either have a small dense center (so-called 'white star') or a radiolucent center (so-called 'black star'). Even though the risk of malignancy is higher with the former imaging features, the latter may also be associated with malignancy (invasive or DCIS) in up to $20 \%$ of the cases. Unless an architectural distortion corresponds to scarring or is proven as superimposition (after additional views), no reliable mammographic sign exists that could allow the exclusion of malignancy [40-43]. On US, radial scars may be associated with a hypoechoic (mostly small) mass; they may exhibit an architectural distortion or shadowing [43-45]. Up to $1 / 3$ of the radial lesions show no abnormality on US. Even though (partly based on the lower detection rate) US may be slightly more specific than mammography, no sonographic sign exists either that could exclude malignancy in case of an architectural
Fig. 4. Patient with histologically proven lobular neoplasia grade 2. Meanwhile, the multiple areas of enhancement have not changed for more than 5 years.

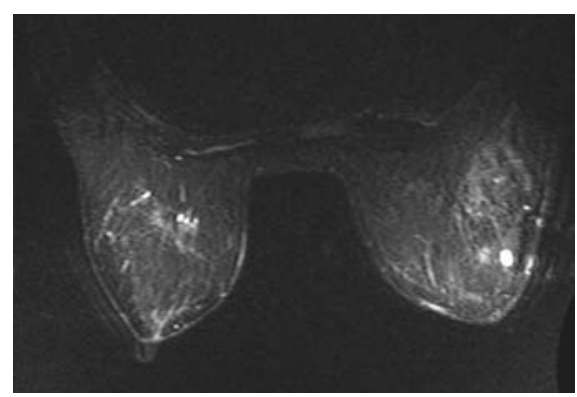

Fig. 5. Radial scar with atypias, diagnosed at VABB and confirmed at surgery.

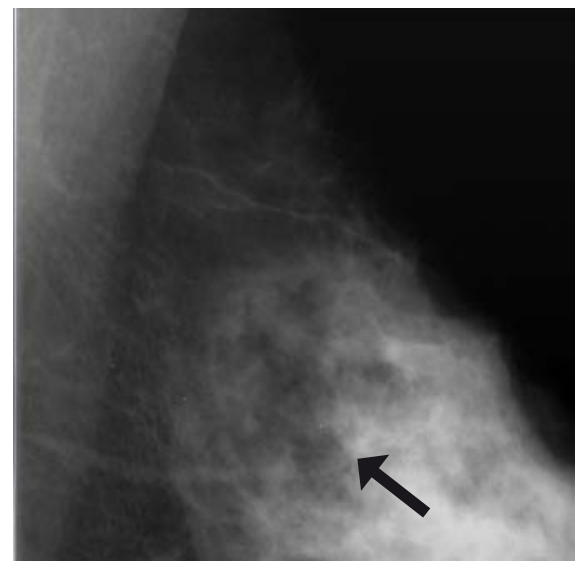

Fig. 6. Radial scar, detected by mammography. On US, a hypoechoic nodule is seen in the center of the lesion. Final diagnosis: RSL without atypias.

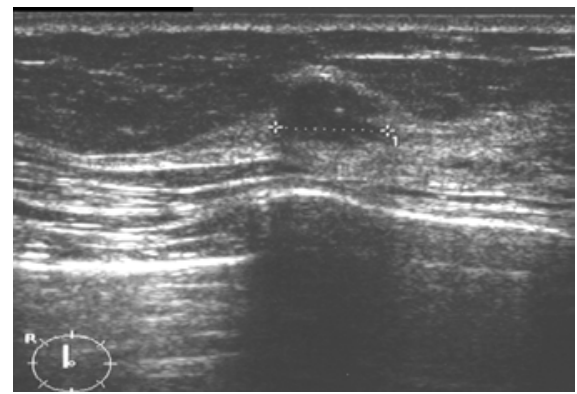

distortion [43, 45]. Figures 5 and 6 give examples of mammographic and sonographic appearances of RSLs.

On MRI, radial scars mostly exhibit low or delayed enhancement. However, exceptions to this observation exist. Furthermore, there exists overlap with the MR features of early malignancy (tubular carcinoma and DCIS), which also may exhibit absent or low and delayed enhancement. Overall, published sensitivity and specificity ranges around $85 \%$, a result that does not permit to reliably exclude malignancy [46, 47].

The diagnosis of an RSL by CNB is associated with a rate of $9-17 \%$ underestimates of DCIS or invasive breast cancer $[10,22,42]$. With VABB, the rate of underestimates decreases. Linda et al. reported a rate of $5 \%$ underestimates in 19 cases of RSL proven by 11 G VABB [42]. Tennant et al. [48] and Resetkova et al. [49] reported no underestimates among 18 or 80 lesions diagnosed as RSL at $11 \mathrm{G} \mathrm{VABB,}$ respectively. They conclude that complete removal at $11 \mathrm{G}$ 
$\mathrm{VABB}$ with interdisciplinary consensus concerning the result may in the future allow a reduction of the number of excisions of those RSLs without atypias.

\section{Papillary Lesions}

Papillary lesions may be detected by imaging or may present as bloody nipple discharge, which then should cause imaging evaluation (using mammography and US). There is increasing controversy about the use of galactography, while preliminary results of MRI appear promising in this indication [50]. On galactography, papillary lesions cause filling defects, irregularities of the involved $\operatorname{duct}(\mathrm{s})$, or a stop at the anterior margin of the obliterated $\operatorname{duct}(\mathrm{s})$.

On mammography, papillary lesions may present as mass with or without microcalcifications, as microcalcifications only, or may not be visible. Papillary lesions may also be contained in RSLs (see above).

On US, papillary lesions may be visible as hypoechoic mass or as complex cystic lesion. They may also present with dilated ducts that are not anechoic. Even though a homogenous echo pattern and a well-circumscribed margin of a papilloma $[51,52]$ are indicative of a benign lesion, mammographic, sonographic and galactographic features do not allow a reliable distinction.

While MRI may help to exlude malignancy in cases of nipple discharge with no mammographic or sonographic findings, a detectable mass or suspicious area of microcalcifications requires histopathological assessment [50]. While - according to our and other authors' experience [14] - enhancing benign and malignant papillary lesions may exhibit overlapping morphological and dynamic MR features, absent enhancement may help exclude malignancy with a high negative predictive value [50].

Histopathological diagnosis of needle biopsy is considered challenging. Based on a literature review, Ueng et al. recom-

Fig. 7. Benign papilloma, removed at VABB. For these lesions, excision is not necessary if the lesion is excised by VABB.

Fig. 8. LIN 2 and FEA diagnosed at $\mathrm{VABB}$ and confirmed by excision. Prognostically, the leading lesion is LIN 2 , the microcalcifications were associated with FEA.
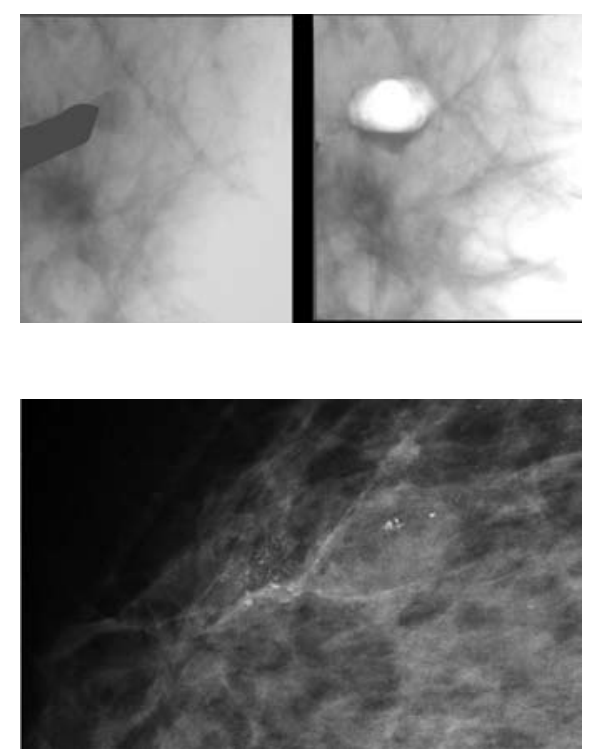

mend surgical excision for all papillomas that have not been completely removed at CNB [53]. This is confirmed by the published negative predictive value of CNB diagnoses of benign papillomas that ranges around $78-100 \%$. Whenever atypias are diagnosed at $\mathrm{CNB}$, the negative predictive value even drops to about $50 \%$ [10, 22, 54-57].

To date, increasing data exist confirming that small papillomas can be completely removed by VABB, as also shown in figure 7. For these lesions, the reported rate of underestimates appears to be very low, ranging from 0 to $5 \%$ [48, 51, 58, 59], and follow-up instead of excision may be justified after close imaging-histopathological correlation.

\section{Columnar Cell Lesions and FEA}

Columnar cell lesions (CLL) and FEA are usually detected as fine amorphous microcalcifications (often with ductal arrangement or some pleomorphism) [60]. In some cases, CLL may present as a (small) uncharacteristic mass on mammography or US.

Based on histopathological morphology and molecular features, CLL may represent the link between benign hyperplasia and low-grade DCIS. By definition, only FEA contains cell atypias and thus may have clinical significance [61, 62]. Figure 8 gives an example.

FEA may coexist with higher-grade lesions such as $\mathrm{ADH}$, LIN, DCIS or invasive (e.g. tubular) carcinoma. Whereas FEA is frequently associated with higher-grade lesions (approximately $35 \%$ ), pure FEA appears to have a low risk of associated malignancy.

Thus, when FEA is detected as the leading lesion using $\mathrm{CNB}$, excision is usually recommended.

The rate of upgrades after a VABB diagnosis of pure FEA ranges from 0 to $20 \%$ [63, 64]. Based on 40 cases diagnosed as FEA by VABB, David et al. reported that a size below $10 \mathrm{~mm}$ and complete removal yielded no upgrade [65]. Provided these results can be confirmed by further research, these considerations may become important to reduce benign excisions prompted by imaging findings.

\section{Fibroepithelial Lesions}

Fibroepithelial B3 lesions include phyllodes tumors and comparable lesions that have similarities to fibroadenomas and phylloides tumors. They usually present as oval mass (like fibroadenomas) without and sometimes with calcifications. Many of these lesions are well circumscribed (fig. 9). Larger lesions may have ill-defined margins. The characterisics of the phyllodes tumor include its fast growth and sometimes cystic spaces on US. Unless completely excised, they tend to recur. Malignancy is infrequent, but can only be excluded after complete excision [10, 22]. Therefore, all phyllodes tumors as well as the rare other fibroepithelial lesions that are classified as B3 (fibroadenomas or myxoid lesions that exhibit histopathological changes suspicious of phylloides tumors) require excision. 
Fig. 9. (a) Mammographic presentation of a benign phyllodes tumor; (b) sonographic presentation of a benign phyllodes tumor.
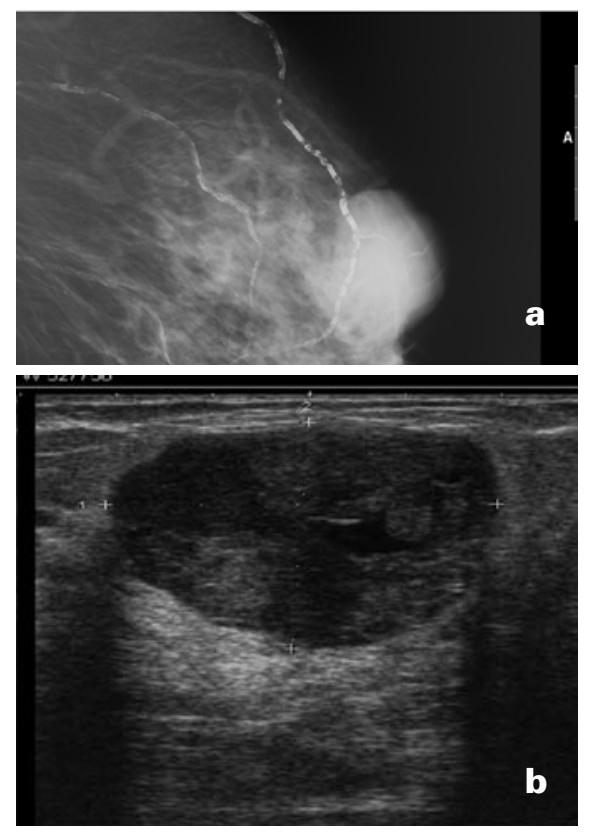

\section{Other B3 Lesions}

Further rare lesions may be classified as B3 lesions at minimal invasive biopsy. These include for example mucocele-like lesions, mucinous or spindle cell lesions. The data on these lesions are very limited. Therefore, to date, excision is recommended.

\section{Discussion}

B3 lesions are composed of several different entities. These entities are grouped together since they have a comparable risk of malignancy, which is higher than that of benign changes. Thus, similar risk considerations need to be made for B3 lesions.

As supported by the results of genetic profiling, B3 lesions may indeed represent the link between early malignancy and benign changes. Even though they are known to have an unknown biological potential, they are still classified as benign changes, which also takes into account that they are non-obligatory precursors of malignancy and thus may stay in the breast forever, without changing and without threatening the patient's life.

B3 lesions require special attention for the following reasons:

- Their histopathological diagnosis and distinction from other entities is still a challenge, requiring a high level of expertise. Inter-observer variability between pathologists mainly concentrates on these entities. Furthermore, knowledge on their presentation and any associated risk is still growing.

- They may exhibit changes like early malignancy, but their distinction from early malignancy may simply not be possible based on small or very small volumes of tissue.
- Their imaging features may overlap with those of benign or early malignant change.

- Part of the B3 lesions is not visible by imaging and has no distinct imaging features. These usually constitute incidental findings.

- The presence of a B3 lesion may indicate a generally increased bilateral risk of breast cancer.

- Depending on the type of the B3 lesion, the lesion may be a non-obligatory precursor of malignancy that might develop into malignancy.

- B3 lesions may also occur adjacent to higher-grade lesions (DCIS or invasive cancer). Thus, the diagnosis of a B3 lesion may be the only indicator of an adjacent breast cancer, which, due to a sampling error, was not diagnosed at percutaneous breast biopsy.

- Some of the B3 lesions may occur throughout the breast. Removing the complete breast tissue should only be considered at high risk.

- However, many of the B3 lesions may never develop further or will not do so before the woman dies from another cause. (Here, one should consider that mortality of DCIS grade 1 ranges around $1 \%$.) For B3 lesions, mortality is even lower. Also, follow-up might allow early detection of malignancy if it really has occurred.

Overall, the decision for or against excision or for or against chemoprevention or follow-up is not easy. Based on the above said, not excising a B3 lesion may carry the risk of missing a higher-grade lesion (DCIS or invasive breast cancer) associated with the B3 lesion. Excising the lesion, however, may mean overtreatment of those cases in which the B3 lesion is not associated with a higher-grade lesion or would not develop into malignancy or even a life-threatening cancer in this location. Excising an extended B3 lesion (for example LIN 1) may even be inadequate when considering the patient's risk Also, the overall prevalence of B3 lesions in the healthy population is not yet known. Based on the above considerations, the best-suited recommendation has to be found for each individual patient whenever such a lesion is detected.

In order to make this decision, to date, no single solution can be given. International guidelines recommend that these cases be discussed in the interdisciplinary team and decided for each individual patient.

For this decision, the following factors should be considered:

- Imaging before, during and after the intervention should be available together with the specimen radiograph(s) and histopathology (if possible, histopathology slides).

- Based on imaging (degree of suspicion, demonstration of correct needle position and of the lesion contained in the specimen radiograph and - in cases of $\mathrm{VABB}$ - on images before/after $\mathrm{VABB}$ ), it must be decided whether the biopsy is representative of the lesion that initially was of concern on imaging. For example, microcalcifications are, in general, not explained by pure LIN 1 or 2 . If this is not the 
case, re-biopsy remains necessary to solve the initial problem.

- The overall risk of the histopathological lesion for malignancy (in the same location!) needs to be considered: ADH and LIN 3 (pleomorphic LCIS) are considered B3 lesions at high risk, requiring excision or even further treatment, respectively. LIN 2 or FEA concern lesions of somewhat lower risk, for which follow-up or excision may be considered. RSLs or papillary lesions without atypias are associated with a low risk. For small lesions that are removed at $\mathrm{VABB}$, follow-up may be considered. Pure LIN 1 usually is an incidental finding and a mild risk indicator. Thus, whenever the initial diagnostic problem is solved, LIN 1 should not be excised.

- Based on histopathological assessment of the available tissue and on the imaging information, the expected extent of the B3 lesion should be assessed: Both the risk of malignancy and the risk of an underestimate increase with increasing lesion extent.

- Lesion size and percentage of lesion removal should be considered: The risk of malignancy decreases with lesion size and increases with the percentage of removal (due to decreasing sampling error). The biopsy method (VABB versus $\mathrm{CNB}$ ) and the amount of acquired tissue are of importance. Thus, for low-risk lesions (RSLs $<10 \mathrm{~mm}$, small papillomas without atypias, possibly FEA, possibly LIN 2) follow-up should be considered if the lesion was already removed by $\mathrm{VABB}$.

- If follow-up is considered, the expected reliability of imaging follow-up should be considered (taking into account the surrounding tissue and the appearance of the lesion). Furthermore, the recommended imaging follow-up and the availability of these methods need to be considered.

- Further risk factors may increase the risk of malignancy (family history, personal history of breast cancer, and others).

- Other conditions that might increase the risk of surgery or limit the patient's life expectancy (e.g. patient age) have to be taken into account.

In summary, many factors need to be considered, all of which may vary individually. An interdisciplinary team is indispensable to consider and weigh all available information to find an individually adapted, optimum recommendation. Eventually, the patient's wish has to be considered as well.

While our knowledge on B3 lesions is still growing, it is important to collect and evaluate this information. Only continuous data collection and evaluation will allow reaching a better understanding of radiological appearance, of histomorphological appearance and of potential future tests (like genetic profiling). With increasing knowledge, risk might in the future be assessed more accurately. This might eventually allow further optimization of the treatment, to better limit it to those women at risk and avoid overtreatment in women at low risk.

\section{Conflict of Interest}

The authors declare that there are no potential conflicts of interests.

\section{References}

1 Perry N, Broeders M, de Wolf C, Toernberg S, Holland R, von Karsa L (eds): European Guidelines for Quality Assurance in Breast Screening and Diagnosis. Luxembourg: Office for Official Publications of the European Communities, 2006, pp 221-256.

2 Albert US, Altland H, Duda V, Engel J, Geraedts M, Heywang-Köbrunner S, Hölzel D, Kalbheim E, Koller M, König K, Kreienberg R, Kühn T, Lebeau A, Nass-Griegoleit I, Schlake W, Schmutzler R, Schreer I, Schulte H, Schulz-Wendtland R, Wagner U, Kopp I: 2008 update of the guideline: early detection of breast cancer in Germany. J Cancer Res Clin Oncol 2009;135:339-354.

$\checkmark 3$ Silverstein M, Interdisciplinary Consortium (Burak WE, Clough K, Edwards MJ, Fine RE, Gittleman MA, Harms SE, Harness JK, Heywang-Köbrunner SH, Holland R, Krag DN, Kuske RR, Lagios MD, Page DL, Press M, Recht A, Robinson D, Rubin E, Schwartz GF, Tabar L, Vicini F, Waisman J): International consensus conference on image-detected breast cancer: state of the art diagnosis and treatment. J Am Coll Surg 2001;193:297-302.

4 Heywang-Köbrunner SH, Schreer I, Decker T, Böcker W: Interdisciplinary consensus on the use and technique of vacuum assisted stereotactic breast biopsy. Eur J Radiol 2003;47:232-236.
5 Heywang-Köbrunner SH, Sinnatamby R, Schreer I, Consensus Group: Inter-disciplinary consensus on the uses and technique of MR-guided vacuum assisted breast biopsy (VAB): Results of a European consensus meeting. Eur J Radiol 2009:72:289-294.

6 Liberman L: Clinical management issues in percutaneous core breast biopsy. Radiol Clin North Am 2002;40:483-500.

7 Lee AH, Denley HE, Pinder SE, et al.: Excision biopsy findings of patients with breast needle core biopsies reported as suspicious of malignancy (B4) or lesion of uncertain malignant potential (B3). Histopathology 2003;42:331-336.

$\checkmark 8$ Houssami N, Ciatto S, Ellis I, Ambrogetti D: Underestimation of malignancy of breast coreneedle biopsy: concepts and precise overall and category-specific estimates. Cancer 2007;109:487495.

$\checkmark 9$ Dillon MF, McDermott EW, Hill AD, et al.: Predictive value of breast lesions of 'uncertain malignant potential' and 'suspicious for malignancy' determined by needle core biopsy. Ann Surg Oncol 2007;14:704-711.

10 El-Sayed ME, Rakha EA, Reed J, et al.: Predictive value of needle core biopsy diagnoses of lesions of uncertain malignant potential (B3) in abnormalities detected by mammographic screening. Histopathology 2008;53:650-657.
1 Kettritz U, Rotter K, Schreer I, Murauer M, Schulz-Wendtland R, Peter D, Heywang-Köbrunner SH: Stereotactic vacuum-assisted breast biopsy in 2874 patients: a multicenter study. Cancer 2004;100:245-251.

12 Fahrbach K, Sledge I, Cella C, Linz H, Ross SD: A comparison of the accuracy of two minimally invasive breast biopsy methods: a systematic literature review and meta-analysis. Arch Gynecol Obstet 2006;274:63-73.

13 Heywang-Köbrunner SH, Nährig J, Hacker A, Hertlein M, Sedlacek S, Höfler H: Evaluation of B3-lesions diagnosed at percutaneous biopsy and surgical results after excision. EJC 2010;(suppl), in press.

14 Linda A, Zuiani C, Bazzocchi M, et al.: Borderline breast lesions diagnosed at core needle biopsy: can magnetic resonance mammography rule out associated malignancy? Preliminary results based on 79 surgically excised lesions. Breast 2008;17:125-131.

15 Johnson NB, Collins LC: Update on percutaneous needle biopsy of nonmalignant breast lesions. Adv Anat Pathol 2009;16:183-195.

16 Perlet C, Heywang-Köbrunner SH, Heinig A, et al.: Magnetic resonance-guided, vacuum-assisted breast biopsy: results from a European multicenter study of 538 lesions. Cancer 2006;106:982-990. 
17 Han BK, Schnall MD, Orel SG, Rosen M: Outcome of MRI-guided breast biopsy. AJR Am J Roentgenol 2008;191:1798-1804.

18 Liberman L, Bracero N, Morris E, et al.: MRIguided 9-gauge vacuum-assisted breast biopsy: initial clinical experience. AJR Am J Roentgenol 2005;185:183-193.

19 Malhaire C, El Khoury C, Thibault F, et al.: Vacuum-assisted biopsies under MR guidance: results of 72 procedures. Eur Radiol 2010;20:1554-1562.

20 Fischer U, Schwethelm L, Baum FT, et al.: Effort, accuracy and histology of MR-guided vacuum biopsy of suspicious breast lesions - retrospective evaluation after 389 interventions. Rofo 2009;181:774-781.

21 Port ER, Park A, Borgen PI, et al.: Results of MRI screening for breast cancer in high-risk patient with LCIS and atypical hyperplasia. Ann Surg Oncol 2007;14:1051-1057.

22 Houssami N, Ciatto S, Bilous M, Vezzosi V, Bianchi S: Borderline breast core needle histology: predictive values for malignancy in lesions of uncertain malignant potential (B3). Br J Cancer 2007;96:1253-1257.

23 Londero V, Zuiani C, Linda A, et al.: Lobular neoplasia: core needle breast biopsy underestimation of malignancy in relation to radiologic and pathologic features. Breast 2008;17:623-630.

24 Jackman RJ, Birdwell RL, Ikeda DM: Atypical ductal hyperplasia: can some lesions be defined as probably benign after stereotactic 11-gauge vacuum-assisted biopsy, eliminating the recommendation for surgical excision? Radiology 2002;224:548554.

25 Eby PR, Ochsner JE, DeMartini WB, Allison KH, Peacock S, Lehman CD: Frequency and upgrade rates of atypical ductal hyperplasia diagnosed at stereotactic vacuum-assisted breast biopsy: 9- versus 11-gauge. AJR Am J Roentgenol 2009;192:229 234.

26 Sohn V, Arthurs Z, Herbert G, Keylock J, Perry J, Eckert M, Fellabaum D, Smith D, Brown T: Atypical ductal hyperplasia: improved accuracy with the 11-gauge vacuum-assisted versus the 14-gauge core biopsy needle. Ann Surg Oncol 2007;14:2497-2501.

27 Plantade R, Hammou JC, Gerard F, Chanalet I, Aubanel D, David-Bureau M, Scotto A, Fighiera M, Gueret S, Lo Monaco L: Ultrasound-guided vacuum-assisted biopsy: review of 382 cases. J Radiol 2005;86(Pt 1):1003-1015.

28 Pandelidis S, Heiland D, Jones D, Stough K, Trapeni J, Suliman Y: Accuracy of 11-gauge vacuum-assisted core biopsy of mammographic breast lesions. Ann Surg Oncol 2003;10:43-47.

29 Jackman RJ, Marzoni FA Jr, Rosenberg J: Falsenegative diagnoses at stereotactic vacuum-assisted needle breast biopsy: long-term follow-up of 1,280 lesions and review of the literature. AJR Am J Roentgenol 2009;192:341-351.

30 Margenthaler JA, Duke D, Monsees BS, et al.: Correlation between core biopsy and excisional biopsy in breast high-risk lesions. Am J Surg 2006;192:534-537.

31 Jang M, Cho N, Moon WK, Park JS, Seong MH, Park IA: Underestimation of atypical ductal hyperplasia at sonographically guided core biopsy of the breast. AJR Am J Roentgenol 2008;191:1347-1351.

32 Haagensen CD, Lane N, Lattes R, Bodian C: Lobular neoplasia (so-called lobular carcinoma in situ) of the breast. Cancer 1978;42:737-769.

33 Page DL, Dupont WD, Rogers LW, Rados MS Atypical hyperplastic lesions of the female breast. A long-term follow-up study. Cancer 1985;55:26982708
34 Contreras A, Sattar H: Lobular neoplasia of the breast: an update. Arch Pathol Lab Med 2009;133:1116-1120.

35 Sneige N, Wang J, Baker BA, Krishnamurthy S, Middleton LP: Clinical, histopathologic, and biologic features of pleomorphic lobular (ductallobular) carcinoma in situ of the breast: a report of 24 cases. Mod Pathol 2002;15:1044-1050.

36 Fadare O, Dadmanesh F, Alvarado-Cabrero I, et al.: Lobular intraepithelial neoplasia [lobular carcinoma in situ] with comedo-type necrosis: A clinicopathologic study of 18 cases. Am J Surg Pathol 2006;30:1445-1453.

37 Chivukula M, Haynik DM, Brufsky A, Carter G, Dabbs DJ: Pleomorphic lobular carcinoma in situ (PLCIS) on breast core needle biopsies: clinical significance and immunoprofile. Am J Surg Pathol 2008;32:1721-1726.

38 Mahoney MC, Robinson-Smith TM, Shaughnessy EA: Lobular neoplasia at 11-gauge vacuum-assisted stereotactic biopsy: correlation with surgical excisional biopsy and mammographic follow-up. AJR Am J Roentgenol 2006;187:949-954.

39 Elsheikh TM, Silverman JF: Follow-up surgical excision is indicated when breast core needle biopsies show atypical lobular hyperplasia or lobular carcinoma in situ: a correlative study of 33 patients with review of the literature. Am J Surg Pathol 2005;29:534-543.

40 Alleva DQ, Smetherman DH, Farr GH Jr, Cederbom GJ: Radial scar of the breast: radiologic-pathologic correlation in 22 cases. Radiographics 1999;19:S27-S35.

41 Bouté V, Goyat I, Denoux Y, et al.: Are the criteria of Tabar and Dean still relevant to radial scar? Eur J Radiol 2006;60:243-249.

42 Linda A, Zuiani C, Furlan A, et al.: Radial scars without atypia diagnosed at imaging-guided needle biopsy: how often is associated malignancy found at subsequent surgical excision, and do mammography and sonography predict which lesions are malignant? AJR Am J Roentgenol 2010;194:11461151.

43 Egyed Z, Péntek Z, Járay B, et al.: Radial scarsignificant diagnostic challenge. Pathol Oncol Res 2008;14:123-129.

44 Lee E, Wylie E, Metcalf C: Ultrasound imaging features of radial scars of the breast. Australas Radiol 2007;51:240-245.

45 Grunwald S, Heyer H, Kühl A, et al.: Radial scar/ complex sclerosing lesion of the breast - value of ultrasound. Ultraschall Med 2007;28:206-211.

46 Pediconi F, Occhiato R, Venditti F, et al.: Radial scars of the breast: contrast-enhanced magnetic resonance mammography appearance. Breast J 2005;11:23-28.

47 Baum F, Fischer U, Füzesi L, et al.: The radial scar in contrast media-enhanced MR mammography. Rofo 2000;172:817-823.

48 Tennant SL, Evans A, Hamilton LJ, et al.: Vacuum-assisted excision of breast lesions of uncertain malignant potential (B3) - an alternative to surgery in selected cases. Breast 2008;17:546-549.

49 Resetkova E, Edelweiss M, Albarracin CT, Yang WT: Management of radial sclerosing lesions of the breast diagnosed using percutaneous vacuumassisted core needle biopsy: recommendations for excision based on seven years' of experience at a single institution. Breast Cancer Res Treat 2008;Jul 15 [Epub ahead of print].
50 Sardanelli F, Boetes C, Borisch B, Decker T, Federico M, Gilbert F, Helbich T, HeywangKoebrunner SH, Kaiser W, Kerin M, Mansel R, Marotti L, Martincich L, Mauriac L, MeijersHeijboer H, Orecchia R, Panizza P, Ponti A, Purushotham A, Regitnig P, Rosselli Del Turco M, Thibault F, Wilson R: Magnetic resonance imaging of the breast: Recommendations from the EUSOMA working group. Eur J Cancer 2010;46:12961316 .

51 Shin HJ, Kim HH, Kim SM, et al.: Papillary lesions of the breast diagnosed at percutaneous sonographically guided biopsy: comparison of sonographic features and biopsy methods. AJR Am J Roentgenol 2008;190:630-636.

52 Kim TH, Kang DK, Kim SY, et al.: Sonographic differentiation of benign and malignant papillary lesions of the breast. J Ultrasound Med 2008;27:7582.

53 Ueng SH, Mezzetti T, Tavassoli FA: Papillary neoplasms of the breast: a review. Arch Pathol Lab Med 2009;133:893-907.

54 Bennett LE, Ghate SV, Bentley R, Baker JA: Is surgical excision of core biopsy proven benign papillomas of the breast necessary? Acad Radiol 2010;17:553-557.

55 Bernik SF, Troob S, Ying BL, et al.: Papillary lesions of the breast diagnosed by core needle biopsy: 71 cases with surgical follow-up. Am J Surg 2009; 197:473-478.

56 Hayes BD, O'Doherty A, Quinn CM: Correlation of needle core biopsy with excision histology in screen-detected B3 lesions: the Merrion Breast Screening Unit experience. Clin Pathol 2009;62:1136-1140.

57 Skandarajah AR, Field L, Yuen Larn Mou A Benign papilloma on core biopsy requires surgical excision. Ann Surg Oncol 2008;15:2272-2277.

58 Zografos GC, Zagouri F, Sergentanis TN, et al.: Diagnosing papillary lesions using vacuum-assisted breast biopsy: should conservative or surgical management follow? Onkologie 2008;31:653-656.

59 Carder PJ, Khan T, Burrows P, Sharma N: Large volume 'mammotome' biopsy may reduce the need for diagnostic surgery in papillary lesions of the breast. J Clin Pathol 2008;61:928-933.

60 Pandey S, Kornstein MJ, Shank W, de Paredes ES: Columnar cell lesions of the breast: mammographic findings with histopathologic correlation. Radiographics 2007;27(suppl 1):S79-S89.

61 Simpson PT, Gale T, Reis-Filho JS, et al.: Columnar cell lesions of the breast: the missing link in breast cancer progression? A morphological and molecular analysis. Am J Surg Pathol 2005;29:734746.

62 Nährig J: Practical problems in breast screening. Columnar cell lesions including flat epithelial atypia and lobular neoplasia. Pathologe 2008;29(suppl 2):172-177.

63 Kunju LP, Kleer CG: Significance of flat epithelia atypia on mammotome core needle biopsy: Should it be excised? Hum Pathol 2007;38:35-41.

64 Senetta R, Campanino PP, Mariscotti G, et al.: Columnar cell lesions associated with breast calcifications on vacuum-assisted core biopsies: clinical, radiographic, and histological correlations. Mod Pathol 2009;22:762-769.

65 David N, Labbe-Devilliers C, Moreau D: Diagnosis of flat epithelial atypia (FEA) after stereotactic vacuum-assisted biopsy (VABB) of the breast: What is the best management: systematic surgery for all or follow-up? J Radiol 2006;87(Pt 1):16711677 . 